\section{O Marajó de Lisboa}

\section{Por João Meirelles Filho \\ Instituto Peabiru \\ (jmeirelles@peabiru.org.br)}

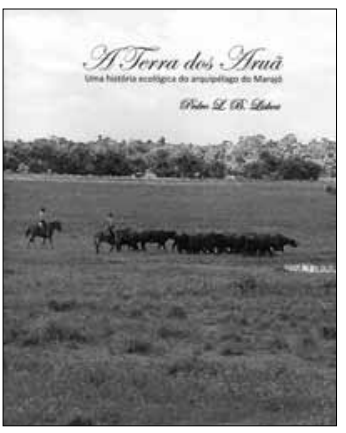

LISBOA, Pedro L. B.

A Terra dos Aruã uma história ecológica do arquipélago do Marajó. Belém: Museu Paraense Emílio Goeldi, 2012. 482 p. il. ISBN 978-85-61377-57-1.

O livro de Pedro Lisboa - "A Terra dos Aruã: uma história ecológica do arquipélago do Marajó" - é uma ótima notícia para a formaç̧ão da tão necessária biblioteca marajoara. Este livro de peso, com capa dura, vistoso, bastante ilustrado, demonstra, em suas 482 páginas, a extensão dos múltiplos interesses do autor, que aborda com maestria tanto os temas de sua prática direta, a botânica, como enfrenta as marés rebojantes da ecologia, etnografia, geografia, economia e história. Dr. Lisboa, pesquisador titular da Coordenação de Botânica do Museu Paraense Emílio Goeldi, é, certamente, um dos maiores 'marajonistas' (especialistas em Marajó). O museu - pioneiro na pesquisa científica sobre $\mathrm{O}$ arquipélago, primeiro com Domingos Soares Ferreira Penna, em meados do XIX, e depois com Emílio Goeldi, já no final do século - cumpre novamente o papel de propalador do conhecimento, vislumbrando mais além dos horizontes acadêmicos.

Há tempos não se publicava em língua portuguesa, para um público eclético, extenso ensaio sobre a região (há bibliografia mais variegada na forma de artigos e capítulos, além de menções breves em livros). Nos últimos 60 anos, cabe mencionar "Ilha do Marajó" (1956), de Nunes Pereira, obra breve, interessante e raramente encontrada; "Amazon Town" (1953), do pesquisador norte-americano Charles
Wagley, publicada em português em 1957 pela Companhia Editora Nacional (como "Uma Comunidade Amazônica"); "Santos e Visagens" (1955), de Eduardo Galvão, aluno de Wagley, também pela Companhia Editora Nacional (a partir da tese de doutorado defendida em 1952, como "The religion of an Amazonian community: a study in culture change"); "A foz do Rio Mar" (1968) e "Marajó, desafios da Amazônia" (1976), ambos do paraense Miranda Neto, esta última republicada pela EDUFPA/Cejup em 1992; e o ensaio fotográfico "Marajó" (1989), do carioca José de Paula Machado, com breve texto de Leandro Tocantins, um coffee-table-book, esgotado. Nas décadas de 1980 e 1990, o valoroso padre Giovani Gallo publicou “Marajó: ditadura das águas" (1981), além de sua autobiografia, de fraca distribuição.

As coisas começaram a mudar se considerarmos as diversas publicações de Denise Schaan a partir de 2000, versando sobre arqueologia, e que têm o mérito de tornar públicos aspectos circunscritos à academia (vide "Marajó: arqueologia, iconografia, história e patrimônio" ou "Marajó - Culturas e Paisagens", este, fruto de parceria entre o Instituto do Patrimônio Histórico e Artístico Nacional IPHAN e a Universidade Federal do Pará - UFPA), além de obras para o público escolar médio local, em parceria com Agenor Sarraf Pacheco e Jane Beltrão.

Nas ciências sociais, apesar de alguma produção em artigos científicos, são raras as publicações vertidas em livro, acessíveis ao grande público, como o primoroso "À Margem dos 'Marajós'” (2006), de Agenor Pacheco. Fortuitamente, no marasmo do interesse de órgãos públicos sobre esta região, maior que sete estados brasileiros, ou Portugal, está o IPHAN, que investe em estudos e publicações, como o fez com "Folias de São Sebastião: um estudo da transmissão musical" (2012), de Líliam Barros e Verena Abufaiad, e com "Muito alem dos campos: arqueologia e história da Amazônia marajoara" (2010), organizado por Denise Schaan e Cristiane Pires Martins (em parceria com a UFPA). Alguns grandes fazendeiros realizaram obras autobiográficas, mas de divulgação restrita e de interesse relativo (como as das famílias Acatauassú, Castro Ribeiro, 
Feio Jr. e Steiner, entre outros, a maior parte editada por Antônio Smith Mesquita), assim como outras memórias locais. Dos órgãos de turismo, nada se publicou.

O fato é que, se um interessado em Marajó consultar o website da Livraria da Folha, não encontrará um livro sequer. Na Livraria Cultura, somente duas obras de Denise Schaan estão disponíveis. Mesmo em sebos se terá dificuldades em encontrar obras sobre o Marajó! Destarte, diante desta seca de livros, Lisboa apresenta um Marajó vasto e complexo.

Adentremos, pois, o Marajó pelas faldas. Nas guardas do livro, uma pequena manada de búfalos deleitase na água rioceânica, certamente sob forte sol, e que farão ali? Espreitariam o dono, que fora à terra e deixara aquela embarcação desocupada, ao galeio da maré? Um ponto forte do livro é que muitas páginas se ocupam em, didaticamente, apresentar, por meio de imagens, processos de produção, características socioeconômicas ou culturais. O mais importante é a honestidade das imagens - este é um Marajó sem pó-de-arroz, sem o floreio habitual de quem o prepara como um cenário para turistas. Lamentase, no entanto, que diversas imagens não apresentem qualidade suficiente para a devida fruição do que prometem apresentar. A diagramação, pouco elaborada, com linhas excessivamente longas, igualmente, não contribui à fluência da leitura. $\bigcirc$ melhor uso da tipografia e a distribuição das imagens tornariam a obra ainda mais atraente.

Em tempo, Pedro escreve em estilo agradável, com frases longas e demoradas, em parágrafos gordos. autor revela-nos, na calma toada, um Marajó de alta complexidade, sem deixar que a pletora de dados científicos torne a temática desinteressante.

Quanto à abrangência, a obra trata o arquipélago do Marajó (e seus doze municípios: Afuá, Anajás, Breves, Cachoeira do Arari, Chaves, Curralinho, Muaná, Ponta de Pedras, Salvaterra, Santa Cruz do Arari, São Sebastião da Boa Vista e Soure). Infelizmente, o autor não abrangeu a mesorregião, o que exigiria incluir outros quatro municípios - Bagre, Portel, Gurupá e Melgaço, que comportam tanto porções insulares, no próprio arquipélago, como continentais.

O primeiro capítulo, "O arquipélago", oferece uma breve apresentação sobre as características físicas. É uma pena que não incorpore os resultados do "Projeto Marajó", do Instituto Nacional de Pesquisas Espaciais (INPE) e outras instituições, que, conforme seu website, trata da "integração de dados biológicos e geológicos do baixo Tocantins - ilha de Marajó: chave na análise da biodiversidade" (INPE, 2005-2009). Este site contém mapas esclarecedores, onde descobrimos, por exemplo, que o Marajó se separou do continente há menos de dez mil anos. Esta seria a feita de demonstrar que o Marajó é bastante vulnerável a mudanças climáticas, pela baixa altitude da maioria de suas terras.

O segundo capítulo, "O homem", é um dos mais instigadores e procura resgatar brevemente a amplitude de sua história, desde os Aruã (aliás, no título da obra) até o período colonial, debruçando-se tanto sobre o patrimônio material, aqui, especialmente, arqueológico e arquitetônico, como o imaterial. $O$ cotidiano do vaqueiro é belamente descrito, com o vagar e o acuro desejáveis. Pontue-se, todavia, que a obra trata largamente sobre o 'homem marajoara', mas pouco da 'mulher marajoara', seja a sua vivência no espaço da casa, do quintal e da roça, seja nas profissões específicas em que 'maestram', como as de parteiras, benzedeiras, marisqueiras e andirobeiras.

O capítulo três - "Fragmentos da história" - trata de temas como a origem do latifúndio marajoara, resultado de cuidadosa pesquisa no Arquivo Ultramarino, em Lisboa, Portugal, e no Arquivo Público do Estado do Pará, em Belém. Aqui, estudiosos do século XIX, especialmente aqueles interessados na adesão do Pará à independência do Brasil e na Cabanagem, encontrarão material rico, seja sobre o Marajó, seja sobre Belém.

É no capítulo quarto - "Economia" - que se sente falta de informações sobre a mesorregião, e não do arquipélago. De qualquer maneira, o autor, profundo conhecedor da economia da pecuária e das diversas formas de extrativismo e agricultura, presenteia-nos com uma 
descrição clara sobre as principais espécies, variedades, raças (no caso dos animais domésticos) em uso econômico e suas características. Sobre a pecuária, assim inicia o texto: "A pecuária apresenta uma tendência à decadência no arquipélago" (p. 158), e prossegue, desenovelando um arrazoado sobre o proclamado.

Em relação ao extrativismo vegetal, o livro é bastante detalhado em contabilizar as espécies de madeira e os produtos florestais não madeireiros. Porém, pouco se aprofunda sobre o fenômeno da demanda pelo fruto do açaí (fato que já leva mais de uma década), que hoje, certamente, se apruma como principal fonte de renda para muitos. Estudos recentes do Instituto de Desenvolvimento Florestal do Estado do Pará (IDEFLOR), do Instituto de Desenvolvimento Econômico, Social e Ambiental do Pará (IDESP), do Museu Paraense Emílio Goeldi (MPEG), da Universidade Federal Rural da Amazônia (UFRA) e do Instituto Peabiru (Silva et al., 2011) nos auxiliam a compreender as cadeias de valor do açaí e como os dados do Instituto Brasileiro de Geografia e Estatística (IBGE) são subnotificados em relação à região.

Isto porque a decadência tanto da exploração e do beneficiamento ilegais da madeira, cujo golpe de misericórdia resultou no fechamento da maior parte das serrarias, especialmente em Breves, como da acima mencionada decadência da pecuária, deixa poucas alternativas de renda à região. Alenta-nos o que, na conclusão deste capítulo, escreve Lisboa:

Apesar do nível de destruição das pouco extensas matas da parte oriental do Marajó, e da ocupação dos campos pela pecuária, a diversidade de mamíferos, répteis e aves ainda merece o adjetivo 'maravilhas', usado pelo naturalista Emílio Goeldi em suas conferências na Europa, no final do século XIX (p. 215).

O capítulo quinto, cunhado como "Canoas e barcos", é um presente etnográfico, incluindo-se o cuidadoso e carinhoso anotar sobre a história da indústria naval artesanal - as partes das embarcações, os estaleiros e sua origem, com um precioso glossário. Por si só, este ensaio de mais de sessenta páginas mereceria uma publicação, pois encontraria público específico.

No sexto capítulo, consolida-se a predileção geográfica de Lisboa pela região dos campos, expresso em "Municípios do leste". Lisboa preferiu uma abordagem mais estatística e descritiva, o que nos priva de uma reflexão mais profunda e questionadora, especialmente diante da crítica situação social e político-institucional, agravada pela concentração de terras e poder. Um dos temas polêmicos sobre o qual o autor logo se posiciona é o apoio à proposta da Hidrovia do Marajó, sem, no entanto, discutir os prós e contras, haja vista que um dos maiores desafios refere-se ao controle (coercitivo, lastreado em interesses imediatos e personalistas e sem estudos de impacto) do acesso à água por grandes fazendeiros, com consequências diretas para a pesca de subsistência e para as populações tradicionais.

A bibliografia neste capítulo demonstra a importância de aprofundar este debate, especialmente a partir de uma análise sociológica e antropológica, inclusive para populações tradicionais e quilombolas, mormente sobre acesso a recursos naturais e direitos básicos. Haveria que se considerar as contribuições de Agenor Pacheco, Willi Bolle, Josebel Fares, Alfredo Wagner de Almeida, entre outros, que expõem o Marajó de uma maneira menos idílica que seus predecessores.

Outro ponto alto do livro é o capítulo sobre DeusMe-Ajude, uma comunidade tradicional cujo espaço foi minuciosamente estudado pelo autor, e que ocupa sessenta páginas da obra. Da mesma forma, este merece ser um opúsculo à parte, no qual se poderia agregar um mapa e ilustrações sobre as paisagens, para torná-lo atraente. Aqui, o conhecimento do autor evidencia-se nas ciências biológicas. Também há que se mencionar o seu interesse etnográfico em descrever a cultura imaterial, como são os casos do preparo da farinha de mandioca, de bebidas (tiborna), da manipulação de açaí, da confecção do artesanato e de outras atividades tradicionais. Seria assaz 
interessante ouvir a voz da comunidade, com citações de sua fala, inclusive nas questões de gênero.

O oitavo capítulo, "Ambientes biológicos, antropogênicos e naturais do Marajó”, é, certamente, o ponto alto da obra. Oferece-nos importante descrição sobre as principais paisagens do Marajó, aqui relacionadas ao que se denomina de região do 'Marajó dos campos', o que o IBGE considera como microrregião do Arari. Para cada ambiente há, ainda, gráficos, tabelas, fotografias e uma lista de espécies. É importante a leitura conjunta do capítulo anterior e deste, pois apresentam o que o autor busca em relação à ecologia da região.

Um pequeno reparo é que seria igualmente interessante explorar as modificações das paisagens em função da criação de gado (bubalino e bovino). Afinal, trata-se de espécies exóticas e recentes no contexto natural, uma vez que, entre outras consequências de sua presença, o pisoteio dos campos durante a seca cria novos caminhos para a água, modificam-se os tesos (montes antropogênicos, principais locais de sítios arqueológicos) e invadem e modificam as florestas de galeria. Seria muito relevante conhecer o impacto potencial de outros fatores, como o acima mencionado controle dos cursos d'água (barragens, represas, canais etc.), a coleta seletiva de espécies madeireiras e não madeireiras, o desmatamento crescente e as queimadas para limpeza de pasto, além de uma questão mais recente - o plantio de arroz, cuja proposta pretende cobrir 300 mil dos 1,7 milhões de hectares de campos.

O autor conclui com um nono capítulo - "Aspectos do perfil social e econômico do Marajó", que abre com um lamento sobre o fato de a região ser "a mais pobre do estado do Pará". O autor pouco se arrisca a propor caminhos, apenas enumera iniciativas mais recentes, como o Plano Marajó, do Governo Federal (2007), e, brevemente, elenca informações sobre unidades de conservação. $\bigcirc$ autor, certamente, poderia contribuir com uma análise acerca do impacto destas unidades de conservação para a socioeconomia, bem como o impacto dos assentamentos agroextrativistas, que atendem mais de 24 mil famílias, em uma das raras iniciativas públicas de reconhecimento de direitos cidadãos no Marajó, e cobrem mais de um milhão de hectares, especialmente no Marajó ocidental (Instituto Peabiru, 2011).

De qualquer forma, o que resulta da leitura de tão importante obra é que se trata de uma referência para consulta permanente, um clássico. É fruto de quem ama a região, de quem a palmilha e vivencia. O MPEG informa que a obra será distribuída a escolas e organizações sociais do Marajó, e isto é muito importante, algo tão raro neste Marajó. Quanto aos demais leitores, quando solicitarem a obra a um livreiro, usem o aboio para tirar os búfalos da água, o Marajó da estagnação:

- Mano, você tem aí o Lisboa do Marajó?

\section{REFERÊNCIAS}

INSTITUTO NACIONAL DE PESQUISAS ESPACIAIS (INPE). Projeto Marajó. 2005-2009. Disponível em: < http://www.dsr.inpe. br/marajo/index.html>. Acesso em: 12 jan. 2013.

INSTITUTO PEABIRU. Viva Marajó: estuda Marajó - Diagnóstico socioeconômico, ambiental e cultural do Arquipélago do Marajó. Belém: Instituto Peabiru, 2011. Disponível em: <http:// institutopeabiru.files.wordpress.com/2012/09/vivamarajoescutamarajo.pdf >. Acesso em: 12 jan. 2013.

SILVA, R. O.; FERREIRA, M. C.; JARDIM, M.; COSTA, P. G. L.; MENEZES, L. Diagnóstico da cadeia de valor do açaí. Relatório Final. Belém: MPEG/Instituto Peabiru, 2011. 